\title{
Minocycline protects against acrylamide-induced neurotoxicity and testicular damage in Sprague-Dawley rats
}

\author{
Khaled Radad1,2*, Yassmin El-Amir², Ahmed Al-Emam ${ }^{1,3}$, Mubarak Al-Shraim¹, \\ Ismaeel Bin-Jaliah ${ }^{4}$, Christopher Krewenka ${ }^{5}$, and Rudolf Moldzio 5 \\ ${ }^{1}$ Department of Pathology, College of Medicine, King Khalid University, P.O.Box: 641, Abha, 61421, Aseer, Saudi Arabia \\ 2 Department of Pathology, Faculty of Veterinary Medicine, Assiut University, Assiut 71526, Egypt \\ ${ }^{3}$ Department of Forensic Medicine and Clinical Toxicology, Faculty of Medicine, Mansoura University, Mansoura 35516, Egypt \\ ${ }^{4}$ Department of Physiology, College of Medicine, King Khalid University, P.O.Box: 641, Abha, 61421, Aseer, Saudi Arabia \\ ${ }^{5}$ Institute of Medical Biochemistry, Department for Biomedical Sciences, University of Veterinary Medicine Vienna, Veterinaerplatz \\ 1, A-1210, Austria
}

\begin{abstract}
This study investigated the protective effects of minocycline against acrylamide (ACR)-induced neurotoxicity and testicular damage in Sprague-Dawley rats. Forty rats were divided into five groups (eight rats each). Group I received saline $(0.5 \mathrm{~mL} / \mathrm{rat}) \mathrm{daily}$ for 10 days and served as the untreated control group. Group II received ACR (30 mg/kg body weight (b.w.)) daily for 10 days. Group III received ACR (30 mg/kg b.w.) daily for 10 days and subsequently minocycline (60 mg/kg b.w.) for five days. Group IV received ACR $(30 \mathrm{mg} / \mathrm{kg}$ b.w.) daily for 10 days followed by saline for five days and served as the control group for the ACR-minocycline-treated group. Group V received minocycline $(60 \mathrm{mg} / \mathrm{kg}$ b.w.) for five days. All treatments were administered orally. Rats in group I and V showed normal locomotor behavior and normal histology of the brain and testes. Administration of ACR (Group II and IV) resulted in weight loss and gait abnormalities. Furthermore, neuronal degeneration in the hippocampus and cerebellum and degeneration of the seminiferous tubular epithelium with formation of spermatid giant cells were observed. Ultrastructurally, ACR specifically damaged spermatogonia and spermatocytes. Acrylamide was also seen to cause a significant increase of malondialdehyde levels in the brain and testes. Treatment of ACR-administered rats with minocycline (Group III) significantly alleviated the loss of body weight and improved locomotor function. Minocycline also ameliorated neuronal degeneration and seminiferous tubular damage and decreased malondialdehyde concentrations. In conclusion, minocycline protects against neurotoxic effects of acrylamide and seminiferous tubular damage. Decreasing lipid peroxidation by minocycline might play a role in such protection. (DOI: 10.1293/tox.2019-0066; J Toxicol Pathol 2020; 33: 87-95)
\end{abstract}

Key words: cerebellum, hippocampus, lipid peroxidation, neurodegeneration, spermatid giant cell

\section{Introduction}

Acrylamide (ACR) is a synthetic monomer with a wide range of industrial applications including fabrication of papers, dyes and plastics, and water and wastewater processing $^{1,2}$. It is also used to manufacture adhesives and permanent press fabrics and in polyacrylamide gels for electrophoresis ${ }^{3}$. In 2002, ACR was discovered to be formed in food exposed to high temperature 4 from asparagine and carbonyl groups of glucose and fructose through the Maillard reaction ${ }^{5}$. Since then, many studies have addressed whether

Received: 18 August 2019, Accepted: 9 December 2019

Published online in J-STAGE: 24 February 2020

*Corresponding author: K Radad

(e-mail: khaledradad@hotmail.com)

C2020 The Japanese Society of Toxicologic Pathology

This is an open-access article distributed under the terms of the Creative Commons Attribution Non-Commercial No Derivatives (c) ${ }_{\mathrm{BY}}{ }_{\mathrm{NC}}$ ND creativecommons.org/licenses/by-nc-nd/4.0/).
ACR carries a potential risk to human health ${ }^{1}$. Several studies have demonstrated that ACR is neurotoxic, genotoxicand carcinogenic, and toxic for the reproductive system ${ }^{6}$.

As a neurotoxic agent, ACR was reported to affect both the central and peripheral nervous system in humans and animals ${ }^{7}$. For instance, Pennisi et al. ${ }^{8}$ found that subchronic exposure of humans to ACR results in muscle weakness, hand and feet numbness, ataxia, and gait abnormalities. Semla et al. ${ }^{9}$ observed that administration of ACR to rats induces foot splay, ataxia, and muscle weakness as far as paralysis of the hind limbs. Moreover, ACR induces direct toxic effects on neuronal cells both in vitro and in vivo. For example, Mehri et al. ${ }^{10}$ showed that ACR decreases the viability of PC12 cells and Abdelall et al. ${ }^{11}$ and Lai et al. ${ }^{12}$ reported progressive degeneration of Purkinje cells and hippocampal neurons by ACR in rats, respectively. ACR was also reported to affect reproductive organs ${ }^{13}$. In this context, Chapin et al. ${ }^{14}$ found that ACR significantly damages male reproductive organs in rodents whereas female rodents appear to be resistant to the reproductive toxicity of ACR.

Minocycline (MIN), a semi-synthetic tetracycline, was 
first synthesized from the natural tetracycline antibiotic by the Lederle laboratories ${ }^{15}$. In addition to its broad-spectrum antibiotic properties, MIN targets a variety of stress-related physiological and pathophysiological processes including inflammation, free radicals, oxidative stress, glutamate excitotoxicity, calcium influx, mitochondrial dysfunction, ischemia, hemorrhage, and edema ${ }^{16}$. In the central nervous system, MIN easily crosses the blood-brain barrier ${ }^{17}$ and protects against neurodegeneration in animal models of ischemia18, Parkinson's disease ${ }^{19}$, Huntington's disease ${ }^{20}$, and amyotrophic lateral sclerosis ${ }^{21}$. So far, only one study investigated the effect of MIN on testicular insults. Orazizadeh et al. ${ }^{22}$ showed that MIN inhibits dexamethasone-induced germ cell apoptosis in the testes of mice compared to those treated with dexamethasone alone. The present study aimed to investigate the potential protective effects of MIN against ACR-induced neurotoxicity and testicular damage in Sprague-Dawley (SD) rats.

\section{Materials and Methods}

\section{Materials}

Caring and handling of experimental animals was conducted in accordance with the guidelines of the European Union Council (86/609/EU). Forty adult male SD rats (6-7 weeks old, 120-140 g) were obtained from the Department of Pharmacology, Faculty of Medicine, Assiut University, Assiut, Egypt. Rats were maintained under standard conditions with 12-h light/dark cycles, $20-22^{\circ} \mathrm{C}$, and $54-60 \%$ humidity. All rats had access to a basal diet and water $a d$ libitum. Acrylamide (CAS number 79-06-1) and MIN (CAS number 13614-98-7) were purchased from Sigma-Aldrich (Steinheim, Germany).

\section{Methods}

Treatment protocol: One week after adaptation, rats were randomly assigned into five groups (eight rats each):

- Group I received normal saline $(0.5 \mathrm{~mL} / \mathrm{rat})$ daily for 10 days and served as a control group for the ACR-treated group.

- Group II received ACR (30 mg/kg b.w.) daily for 10 days.

- Group III received ACR (30 mg/kg b.w.) daily for 10 days and afterward minocycline (60 mg/kg b.w.) for five days.

- Group IV received ACR (30 mg/kg b.w.) daily for 10 days followed by normal saline $(0.5 \mathrm{~mL} / \mathrm{rat})$ for five days and served as control for ACR-minocycline-treated group.

- Group V received minocycline (60 mg/kg b.w.) for five days.

The effective doses of ACR and minocycline, and treatment duration were determined in a pilot study. Clinical signs, most notably motor signs, were used as determinants. Daily doses of ACR and MIN were dissolved in distilled water $(0.5 \mathrm{~mL} / \mathrm{rat})$ and given via a gastric tube. The body weight of all rats was measured at the beginning and the end of each treatment.

Assessment of gait scores: Gait scores were assessed according to the method described by LoPachin et al. ${ }^{23}$. At the end of each treatment, rats were put on the ground and allowed to move freely. Each rat was observed for $3 \mathrm{~min}$ and its gait score was assessed with the following readouts:

- Score 1: Normal gait.

- Score 2: Slightly affected gait showing hind limb weakness, slight ataxia, and foot splay.

- Score 3: Moderately affected gait showing less activity and foot splay.

- Score 4: Severely affected gait showing foot splay and severe weakness and dragging of hind limbs.

Tissue samples: Rats were sacrificed by cervical dislocation at the end of each treatment. Brains and testes were carefully obtained from all treated rats (eight rats/group). Each brain was cut into two hemispheres. The testes were cleaned from adjunct tissues including the epididymis, the weight of both testes of each rat was summed, and the mean was calculated. One brain hemisphere and one testis from each rat were kept in 10\% neutral buffered formalin for histopathological examination. The remaining testis was cut into two halves. One half of the testis was kept in $2.5 \%$ glutaraldehyde solution for transmission electron microscopic (TEM) examination. The other brain hemisphere and half of the testis were frozen in liquid nitrogen and stored at $-80^{\circ} \mathrm{C}$ for measurement of malondialdehyde (MDA), the most prominent and currently used assay for lipid peroxidation.

Histopathology: After fixation in 10\% neutral buffered formalin for 24-48 h, tissue samples were trimmed, dehydrated in a graded ethyl alcohol series, cleared with xylene, and embedded in paraffin wax. Tissue sections of $4 \mu \mathrm{m}$ thickness were cut and stained with hematoxylin and eosin (H\&E). Stained tissue sections were examined under a light microscope (CX31, Olympus, Tokyo, Japan) and photographed using a digital camera (Camedia C-5060, Olympus) ${ }^{24}$.

Counting of degenerated neurons in the hippocampus and the cerebellum: Degenerated pyramidal neurons in the hippocampus showing shrinkage and nuclear pyknosis were counted using the $40 \times$ objective (eight hippocampi/group). Furthermore, degenerated Purkinje cells in the cerebellum were counted in five fields/rat (40 fields/group) at 40× magnification.

Counting of seminiferous tubules containing spermatid giant cells: Three tissue sections were taken at different levels of each testis (24 sections/group). Seminiferous tubules containing spermatid giant cells were counted in five randomly selected fields/section (120 fields/group).

Transmission electron microscopy: Preserved testicular samples in $2.5 \%$ glutaraldehyde solution were trimmed and diced into $1-\mathrm{mm}^{3}$ blocks, fixed in glutaraldehyde solution in $0.1 \mathrm{M}$ sodium cacodylate buffer, $\mathrm{pH} 7.2$, and placed in a thermal box cooled to $4^{\circ} \mathrm{C}$ for $2 \mathrm{~h}$. Afterward, tissue blocks were post-fixed in $1 \%$ osmium tetraoxide in a sodium cacodylate buffer and then dehydrated in an ascending series of ethyl alcohol and embedded in Spurr resin. Ultrathin sections stained with uranyl acetate and lead citrate were examined with a TEM (100 CXII, JEOL, Tokyo, Japan) operated at $80 \mathrm{kV}$ in the Electron Microscopy Unit, Pathology 
Department, College of Medicine, King Khalid University $^{24}$.

Lipid peroxidation measurement: MDA concentrations in the brain and testicular tissues were determined by the double heating method from Draper and Hadley ${ }^{25}$. Briefly, tissue from the brain or testis was homogenized on ice with homogenization solution $(\mathrm{KCl})$ in a ratio of $250 \mu \mathrm{L}$ per 25 $\mathrm{mg}$ of tissue. Homogenates were centrifuged at 1,800 g per min for $10 \mathrm{~min}$ at $4^{\circ} \mathrm{C}$ (ROTIXA/AP, Hettich, Apeldoorn, Netherlands). The supernatant was diluted with $\mathrm{KCl}$ (1:10) to $1 \%$ concentration. Of the diluted supernatant, $100 \mu \mathrm{L}$ was mixed with $200 \mu \mathrm{L}$ of a stock reagent containing $15 \%$ trichloroacetic acid, $0.375 \%$ thiobarbituric acid, and $0.25 \mathrm{M}$ $\mathrm{HCl}$. The mixture was boiled in a water bath for $15 \mathrm{~min}$ and after cooling, centrifuged at $1,000 \mathrm{~g}$ for $10 \mathrm{~min}$. Of the supernatant, $150 \mu \mathrm{L}$ was placed on microplates and the absorbance was read spectrophotometrically at $532 \mathrm{~nm}$ (Genios plate reader, Tecan, Männedorf, Switzerland). MDA levels are expressed as $\mathrm{nmol} / \mathrm{mg}$ protein.

Statistics: Data are expressed as mean \pm standard error of the mean (SEM). Comparisons between different groups were made using ANOVA and post-hoc Tukey's test using IBM SPSS statistics 22 . $\mathrm{P}<0.05$ was considered statistically significant.

\section{Results}

\section{Body and testis weight}

Rats in groups I and $\mathrm{V}$ which received normal saline and MIN, respectively, showed a slight weight gain at the end of the treatment compared to their start weight (Fig. 1A). However, after 10 days, the body weight of ACR-treated rats in group II was significantly decreased by approx. $17 \%$ compared to control rats in group I. Administration of MIN to
ACR-treated rats in group III significantly increased their body weight by approx. $13 \%$ compared to ACR-treated rats in group II. There was no significant difference in the body weight between rats in group II and IV. ACR also reduced testis weight and treatment of ACR-administered rats with MIN increased the weight of testis (Fig. 1B). Both findings did not reach significance.

\section{Gait scores}

At the end of each treatment, gait scores were recorded as mean \pm SEM (Table 1). Vehicle-treated rats in group I showed normal gait (gait score $=1$ ). However, ACR-treated rats in group II showed foot splay and dragging and paralysis of hind limbs with significantly higher gait scores (gait score $=3.71 \pm 0.18$ ) compared to the vehicle-treated rats in group I. Administration of MIN to ACR-treated rats in group III significantly alleviated ACR-induced gait abnormalities and significantly reduced the gait score (gait score $=1.29 \pm 0.18$ ) compared to that of ACR-treated rats. No difference in gait scores between rats in group II and IV were noticed. Treatment of rats with MIN alone did not affect the gait.

\section{Gross pathology}

Gross examination of euthanized rats from all groups showed no apparent lesions except for a slight decrease in the size of the testes in rats from the ACR-treated group.

\section{Histopathology}

H\&E-stained brain sections from the vehicle-treated rats in group I revealed a normal histological architecture of the hippocampus (Fig. 2A) and the cerebellum (Fig. 3A). Treatment of rats with ACR (30 mg/kg b.w.) for 10 days resulted in degeneration of pyramidal neurons in the hippocampus (Fig. 2B) and Purkinje cells in the cerebellum
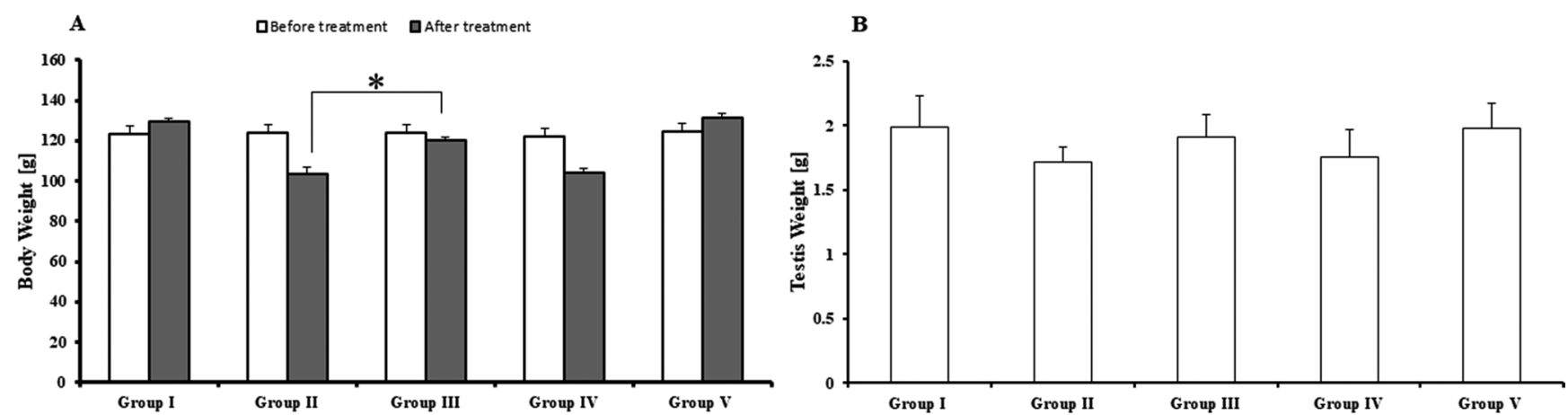

Fig. 1. Body and testis weight. A) Body weight of rats in the different groups. B) Testis weight in the different groups. Values represent the mean \pm standard error of the mean (SEM) $(* \mathrm{p}<0.01)$.

Table 1. Gait Scores (Eight Rats Per Group)

\begin{tabular}{lccccc}
\hline Groups & Group I & Group II & Group III & Group IV & Group V \\
\hline Gait scores & $1.00 \pm 0.00$ & $3.71 \pm 0.18^{*}$ & $1.29 \pm 0.18^{\#}$ & $3.22 \pm 0.16$ & $1.00 \pm 0.00$ \\
\hline *Significant difference between rats in group I and II $\left({ }^{*} \mathrm{p}<0.001\right)$. & \#Significant difference between rats in group II and III $\left({ }^{*} \mathrm{p}<0.001\right)$.
\end{tabular}



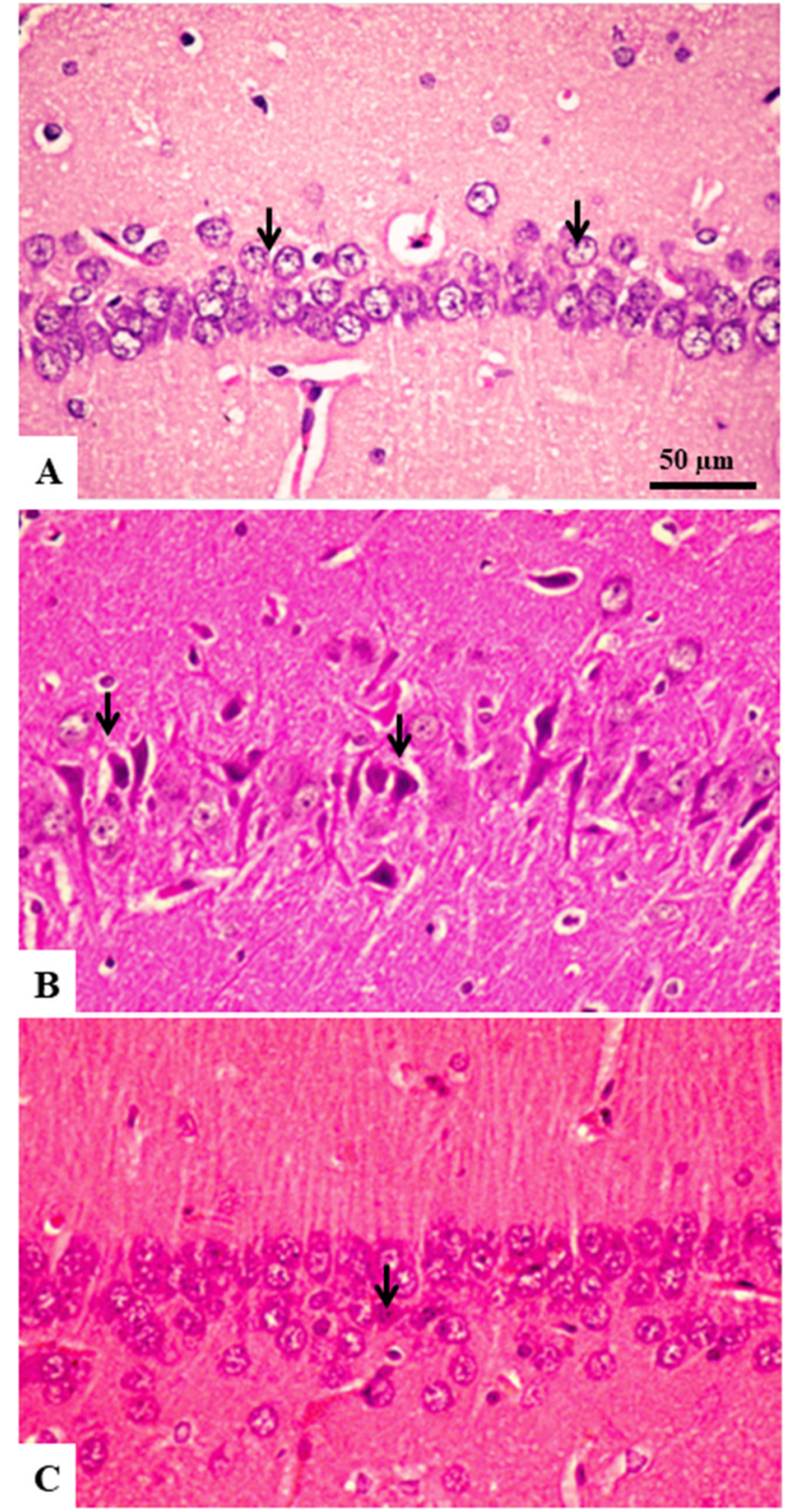

Fig. 2. Representative micrographs of the hippocampus from vehicle-, acrylamide (ACR)-, and ACR+minocycline (MIN)treated rats. A) A normal CA1 subdivision of the hippocampus showing intact small pyramidal neurons with vesicular nuclei (arrows). B) A CA1 subdivision of the hippocampus from ACR-treated rats showing degenerated pyramidal neurons (arrows). Degenerated neurons appear shrunken with pyknotic nuclei. C) A CA1 subdivision of the hippocampus from $\mathrm{ACR}+\mathrm{MIN}$-treated rats revealing the presence of very few degenerated pyramidal neurons (arrow).

(Fig. 3B). Degenerated neurons exhibited shrinkage and nuclear pyknosis. Administration of MIN to ACR-treated rats significantly ameliorated neuronal degeneration in the hippocampus (Fig. 2C) and protected Purkinje cells in the cerebellum (Fig. 3C) compared to rats treated with ACR alone. Rats in group IV showed similar lesions to ACR-treated rats
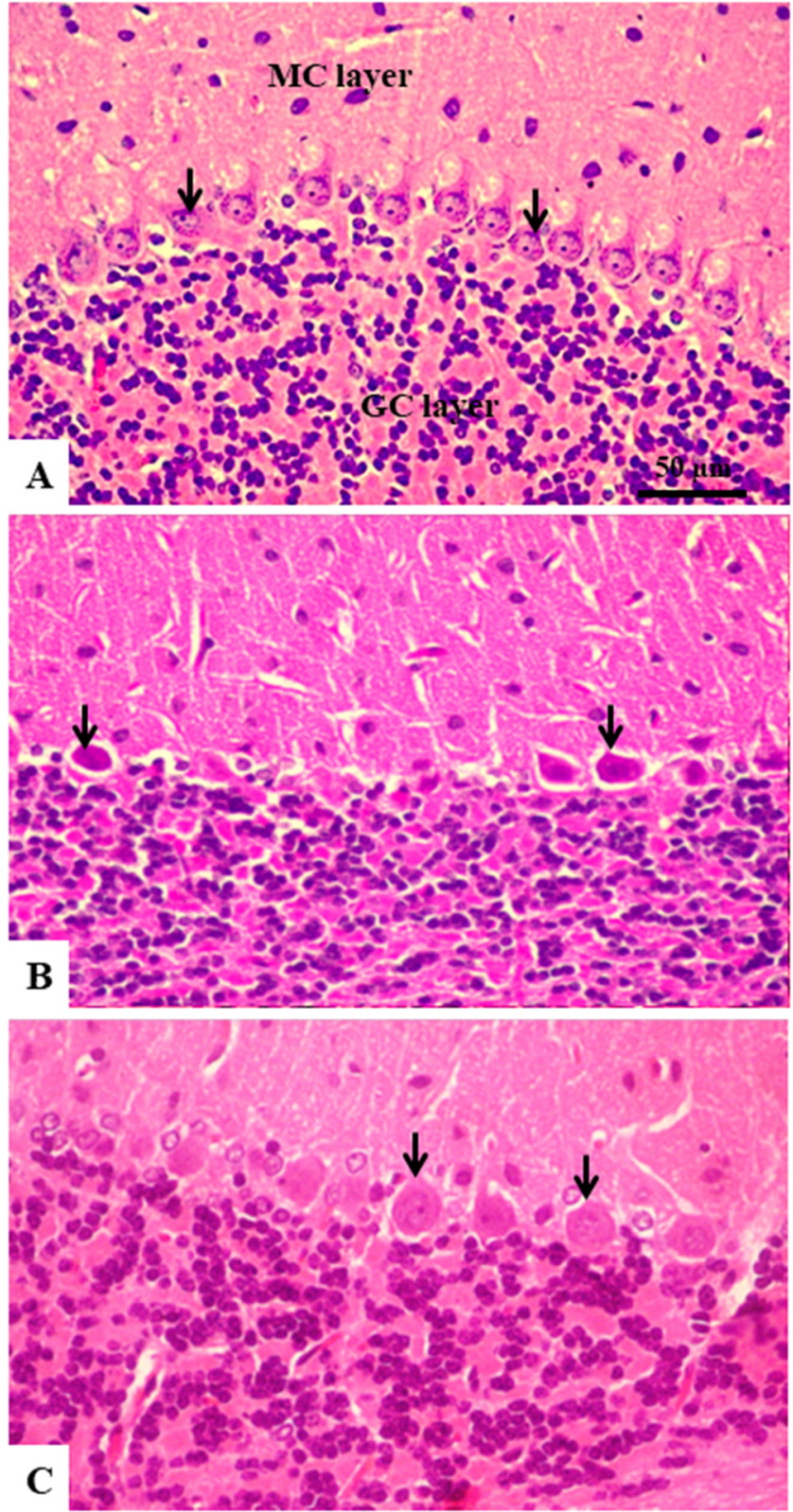

Fig. 3. Representative micrographs of the cerebellum from vehicle-, acrylamide (ACR)-, and ACR+minocycline (MIN)-treated rats. A) A normal cerebellum showing normal architecture with distinct cortical layers: outer molecular (MC) layer, inner granular (GC) layer, and in between the single-cell layer of Purkinje cells. B) A cerebellum from ACR-treated rats showing degenerated Purkinje cells (arrows). C) A cerebellum from $\mathrm{ACR}+\mathrm{MIN}$-treated rats showing more or less normal Purkinje cells (arrows).

in group II. No apparent lesions were seen in MIN-treated rats (data not shown). Table 2 shows the number of degenerated pyramidal neurons in the hippocampus and Purkinje cells in the cerebellum of rats in the different groups.

The testes from vehicle-treated rats in group I showed normal histological appearance of the wall of the seminiferous tubules including myofibroblasts, Sertoli cells, sper- 
Table 2. Number of Degenerated Pyramidal Neurons in the Hippocampus and Purkinje Cells in the Cerebellum

\begin{tabular}{lccccc}
\hline Groups & Group I & Group II & Group III & Group IV & Group V \\
\hline Degenerated pyramidal neurons/hippocampus & $0.33 \pm 0.17$ & $30 \pm 1.83^{*}$ & $4.44 \pm 0.73^{\#}$ & $28 \pm 1.25$ & $0.44 \pm 0.18$ \\
Degenerated Purkinje cells/field & $0.20 \pm 0.07$ & $3.2 \pm 0.13^{*}$ & $0.40 \pm 0.08^{\#}$ & $3.01 \pm 0.20$ & $0.23 \pm 0.07$ \\
\hline
\end{tabular}

*Significant difference between rats in group I and II $\left({ }^{*} \mathrm{p}<0.001\right)$. "Significant difference between rats in group II and III $\left({ }^{*} \mathrm{p}<0.001\right)$.

matocytes, spermatids, and the presence of many sperms in the lumina (Fig. 4A). Leydig cells were located in intervening connective tissue between the seminiferous tubules (Fig. 4A). In ACR-treated rats, we observed degeneration of the seminiferous tubular epithelium, only a few spermatogonia and spermatocytes, absence of spermatids and sperms, and formation of spermatid giant cells (Fig. 4B). Spermatid giant cells were found free in the lumen of the seminiferous tubules and had a large appearance with eosinophilic cytoplasm and numerous nuclei (Fig. 4B). There was also damage to Leydig cells between the seminiferous tubules (Fig. 4B). Treatment of ACR-exposed rats with MIN ameliorated seminiferous tubular degeneration and increased the number of cells in the germinal epithelium including elongated spermatids. MIN also significantly decreased the number of seminiferous tubules containing spermatid giant cells (Fig. 4C) and improved the shape of Leydig cells compared to rats treated with ACR alone. Rats in group IV showed similar lesions to ACR-treated rats in group II. Normal seminiferous tubules were seen in MINtreated rats (data not shown). Table 3 shows the number of seminiferous tubules containing spermatid giant cells in the different groups.

\section{Transmission electron microscopy}

TEM examination of the normal seminiferous tubular epithelium revealed an intact basement membrane, normal Sertoli cells resting on the basement membrane, and spermatogonia and spermatocytes showing a regular nuclear membrane with dispersed chromatin in the nucleus (Fig. 5A). In ACR-treated rats, we observed cytoplasmic vacuolation, electron-dense bodies in the spermatogonia, damaged spermatocytes with an irregular nuclear membrane, and swollen mitochondria (Fig. 5B). Treatment of ACR-exposed rats with MIN decreased the magnitude of the ultrastructural changes compared to those seen in ACRtreated rats (Fig. 5C).

\section{Lipid peroxidation}

Treatment of rats with ACR for 10 days significantly increased MDA concentrations in the brains and testes by approx. $97 \%$ and $84 \%$, respectively, compared to vehicletreated rats. MIN administration to rats for five days following ACR treatment significantly decreased MDA concentrations in the brains and testes by $43 \%$ and $40 \%$, respectively, compared to rats treated with ACR alone. The MDA concentration in group IV rats was nearly the same as in group II rats. MIN alone did not lead to significant changes in MDA concentrations in both brains and testes (Fig. 6).

\section{Discussion}

A large number of people may be exposed to ACR in industry, laboratories, and in daily life activities such as smoking, eating, and drinking water. This highlights the need for studying compounds protecting against ACR toxicity. Accordingly, our study aimed to investigate the ameliorative effects of MIN against ACR-induced neurotoxicity and testicular damage in SD rats. Treatment of rats with ACR significantly decreased body weight by $17 \%$ and caused severe gait abnormalities (gait scores $=3.71 \pm 0.18$ ) including foot splay, hind limbs dragging, and paralysis compared to vehicle-treated rats. This is consistent with studies showing loss of body weight and gait dysfunction following ACR exposure in humans and animal models. For instance, Pennisi et al. ${ }^{8}$ reported that subchronic exposure to ACR causes motor disabilities in humans. Pan et al. ${ }^{26}$ reported that subacute exposure to ACR (40 mg/kg b.w. for 10 ten days) resulted in loss of body weight and motor impairment in rats. The loss in body weight might be attributed to decreasing appetite motivation or low food efficiency ${ }^{26-28}$. The adverse effect of ACR on gait performance was reported to result from decreased release of presynaptic neurotransmitters and damage to nerve terminals ${ }^{29,30}$. In contrast, administration of MIN to ACR-treated rats significantly increased body weight by $13 \%$ and decreased gait scores $(1.29 \pm 0.18)$ compared to rats treated with ACR alone. The improvement of locomotor behavior and general health status might mediate the ameliorative effect of MIN against loss of body weight caused by ACR.

Histopathologically, our results showed that administration of ACR to SD rats induced neuronal degeneration in the hippocampus and the cerebellum. In accordance with our findings, Lai et al. ${ }^{12}$ found that ACR exerts toxic effects on the growth and development of hippocampal neurons. Abdelall et al. ${ }^{11}$ showed shrunken Purkinje cells and nuclear pyknosis in the cerebellum form ACR-treated rats. Dortaj et al. ${ }^{31}$ reported a lower number of Purkinje cells in rats' infants obtained from ACR-treated mothers. El-Bakry et al. ${ }^{32}$ and Al-Gholam et al. ${ }^{33}$ attributed ACR-induced neuronal changes to its oxidative damage and reduced activity of some antioxidant enzymes. In agreement with other studies that reported that ACR also affects the testis, histopathological examination showed that ACR caused degeneration of the seminiferous tubular epithelium and significantly increased seminiferous tubules containing spermatid giant cells in our study. The absence of elongated spermatids in ACR-treated rats indicated stages I-VI compared to stages I-VIII in control rats ${ }^{34}$. Similar histological findings were 


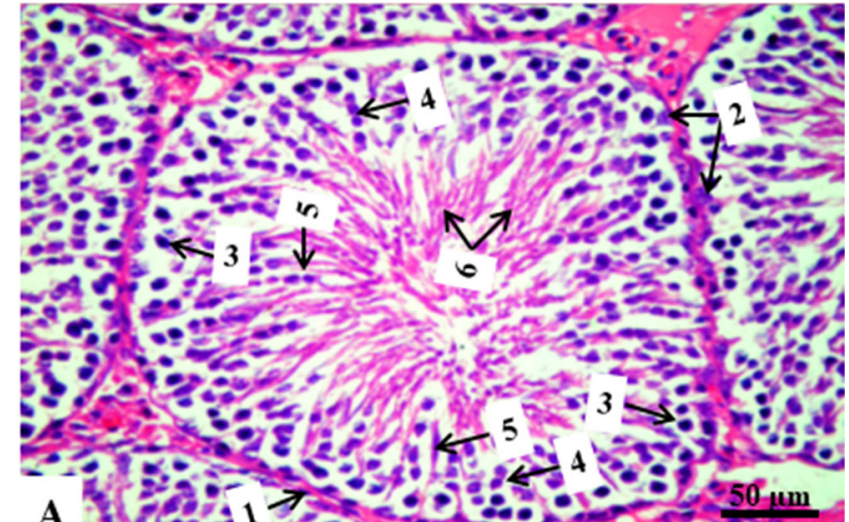

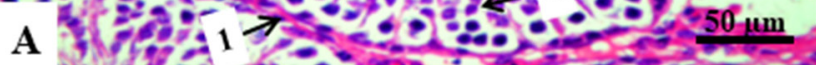
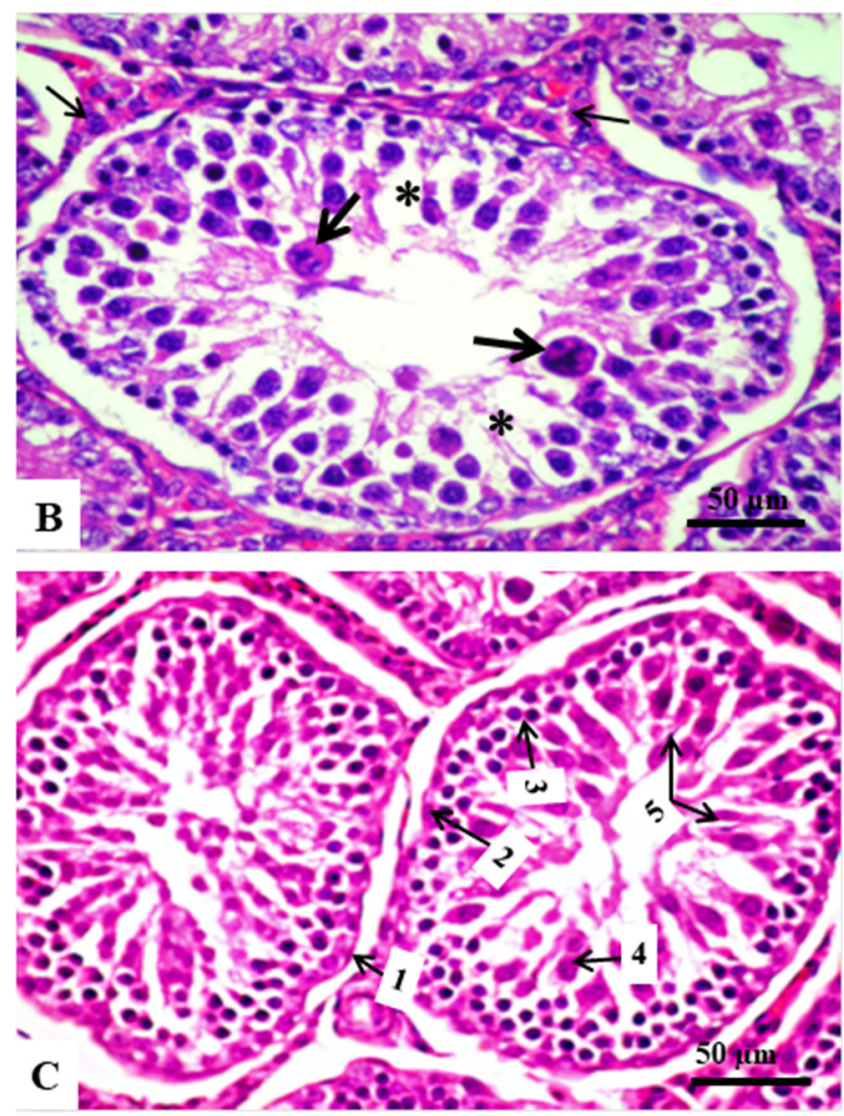

Fig. 4. Representative micrographs of the testes from vehicle-, acrylamide (ACR)-, and ACR+minocycline (MIN)-treated rats. A) Seminiferous tubules from vehicle-treated rats showing normal spermatogenic cell layers including fibroblasts (1), Sertoli cells (2), spermatogonia (3), spermatocytes (4), spermatids (5), spermatozoa (6) (stages I-VIII), and normal Leydig cells (arrows). B) Seminiferous tubules from ACR-treated rats showing depletion of seminiferous tubular cells (asterisks) and formation of spermatid giant cells (arrows) in the lumen (stages I-VI). Damaged Leydig cells (thin arrows). C) Seminiferous tubules from ACR+MIN-treated rats showing restored seminiferous tubular epithelium including myofibroblasts (1), Sertoli cells (2), spermatogonia (3), spermatocytes (4), and spermatids (5) (stages I-VIII)
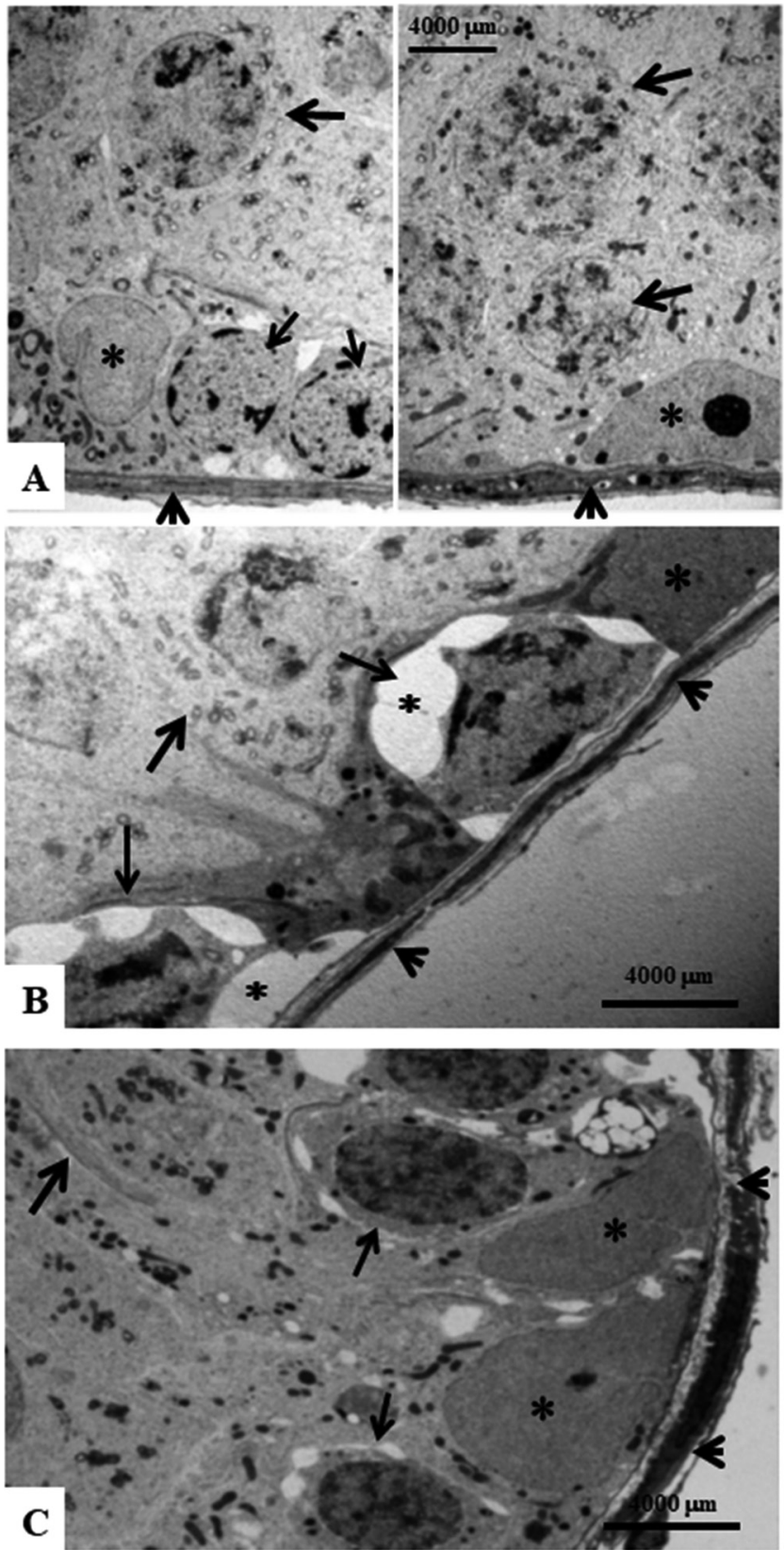

Fig. 5. Representative ultrastructural micrographs of normal, acrylamide (ACR)-treated, and ACR-minocycline (MIN) treated rats. A) Normal seminiferous tubular epithelium showing a normal Sertoli cell resting on the basement membrane (asterisk), spermatogonia (thin arrow), and spermatocytes (thick arrows) showing a regular nuclear membrane with dispersed chromatin in the nucleus. The basement membrane is indicated by arrowheads. B) ACR-treated rats with cytoplasmic vacuolation (small asterisk) and presence of electron-dense bodies in spermatogonia (thin arrows). Spermatocytes showing an irregular nuclear membrane and mitochondrial swelling (thick arrows). The basement membrane is indicated by arrowheads. C) Treatment of ACR-exposed rats with MIN decreased the intensity of ultrastructural changes. The basement membrane is indicated by arrowheads, Sertoli cells by asterisks, spermatogonia by thick arrows, and spermatocytes by thick arrows. 
Table 3. Number of Seminiferous Tubules Containing Spermatid Giant Cells

\begin{tabular}{lccccc}
\hline Groups & Group I & Group II & Group III & Group IV \\
\hline Seminiferous tubules/field & 00.00 & $7.00 \pm 1.26^{*}$ & $1.81 \pm 0.75^{\#}$ & $6.10 \pm 1.13$ & 00.00 \\
\hline
\end{tabular}

*Significant difference between rats in group I and II $\left({ }^{*} \mathrm{p}<0.001\right)$. ${ }^{*}$ Significant difference between rats in group II and III $\left({ }^{*} \mathrm{p}<0.001\right)$.

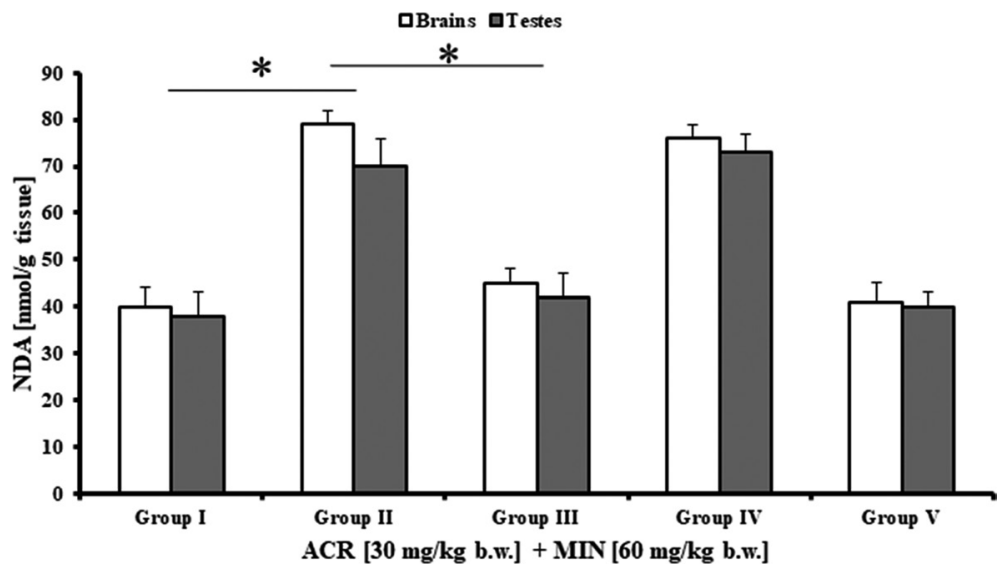

Fig. 6. Malondialdehyde (MDA) measurement in the brains and testes of vehicle-, acrylamide (ACR)-, ACR+minocycline (MIN)-, ACR+saline-, and MIN-treated rats. MDA concentrations are expressed as means \pm standard error of the mean (SEM) (nmol/g tissue) $(* \mathrm{p}<0.01)$.

reported following treatment of rats with $\mathrm{ACR}^{13,35-38}$. ACR was shown by TEM to specifically damage spermatogonia and spermatocytes. Similar to our results, Mustafa ${ }^{35}$ reported that treatment of rats with ACR causes degeneration of spermatogonia and spermatocytes. This explained the cellular depletion in the seminiferous tubular epithelium observed by light microscopy in ACR-treated rats.

Our study showed that MIN significantly alleviated neuronal degeneration in both the hippocampus and cerebellum, markedly restored the seminiferous tubular epithelium including elongated spermatids (stages I-VIII) compared to rats treated with ACR alone, and decreased the number of seminiferous tubules with spermatid giant cells. So far, there have been no reports in the literature describing protective effects of MIN against ACR-induced neurodegeneration and testicular damage. However, protective effects of MIN were reported in some other experimental models of neurodegeneration and testicular toxicity. For example, Radad et al. ${ }^{39}$ revealed a neuroprotective effect for MIN against dopaminergic cell loss induced by long-term rotenone toxicity in primary mesencephalic cell culture. Cronin and Grealy ${ }^{40}$ found that MIN reverses the locomotor deficit and alleviated dopaminergic cell loss induced by 6-OHDA in zebrafish. Park et al. ${ }^{41}$ showed that pretreatment of SD rats with MIN leads to a smaller infarct volume and a higher number of $\mathrm{NeuN}+$ neurons in a transient cerebral ischemia model. Orazizadeh et al. ${ }^{22}$ showed that MIN inhibits dexamethasone-induced germ cell apoptosis in the testes of mice.

Lipid peroxidation is a well-known mechanism of cellular injury and is considered a clear indicator of oxidative stress. Oxidants such as free radicals attack polyunsaturated fatty acids in the plasma membrane, subcellular membranes, lipoproteins, and other lipid-containing molecules ${ }^{42}$. In our study, treatment of rats with ACR increased MDA concentrations in both brain and testicular tissues compared to vehicle-treated rats. Consistent with our study, it was reported previously that treatment of rats with ACR significantly increases MDA levels in the nervous system ${ }^{43-45}$ and the testes ${ }^{36,46}$. Treatment with MIN significantly decreased MDA concentrations in the brain and testicular tissues of ACR-treated rats indicating its antioxidant effects. Similarly, Goudarzi et al. ${ }^{47}$ found that decreasing MDA concentration ameliorates ACR-induced brain lesions in rats. Queiroz et al. ${ }^{48}$ found that MIN effectively prevents lipid peroxidation induced by the dopaminergic transporter inhibitor GBR12909 in the hippocampus of Swiss albino mice. Czerny et al. ${ }^{49}$ showed that MIN decreases lipid peroxidation after hemorrhagic shock in the liver of mice.

In conclusion, our study revealed for the first time that MIN markedly alleviated ACR-induced neurotoxicity and testicular damage in SD rats. Decreasing lipid peroxidation by minocycline might play a role in such protection.

Disclosure of Potential Conflicts of Interest: The authors report no conflict of interest.

Acknowledgments: The authors extend their appreciation to the Deanship of Scientific Research at King Khalid University for funding this work through research groups under grant number R.G.P. 1/125/40. 


\section{References}

1. Taeymans D, Wood J, Ashby P, Blank I, Studer A, Stadler RH, Gondé P, Van Eijck P, Lalljie S, Lingnert H, Lindblom M, Matissek R, Müller D, Tallmadge D, O'Brien J, Thompson S, Silvani D, and Whitmore T. A review of acrylamide: an industry perspective on research, analysis, formation, and control. Crit Rev Food Sci Nutr. 44: 323-347. 2004. [Medline] [CrossRef]

2. Liu S, Jiang L, Zhong T, Kong S, Zheng R, Kong F, Zhang C, Zhang L, and An L. Effect of acrylamide on oocyte nuclear maturation and cumulus cells apoptosis in mouse in vitro. PLoS One. 10: e0135818. 2015. [Medline] [CrossRef]

3. Giese J. Acrylamide in foods. Food Technol. 56: 71-72. 2002.

4. Lofstedt RE. Science communication and the Swedish acrylamide "alarm". J Health Commun. 8: 407-432. 2003. [Medline] [CrossRef]

5. Chu PL, Lin LY, Chen PC, Su TC, and Lin CY. Negative association between acrylamide exposure and body composition in adults: NHANES, 2003-2004. Nutr Diabetes. 7: e246. 2017. [Medline] [CrossRef]

6. Shipp A, Lawrence G, Gentry R, McDonald T, Bartow $\mathrm{H}$, Bounds J, Macdonald N, Clewell H, Allen B, and Van Landingham C. Acrylamide: review of toxicity data and dose-response analyses for cancer and noncancer effects. Crit Rev Toxicol. 36: 481-608. 2006. [Medline] [CrossRef]

7. Kopanska M, Muchacka R, Czech J, Batoryna M, and Formicki G. Acrylamide toxicity and cholinergic nervous system. J Physiol Pharmacol. 69: 1-12. 2018. [Medline]

8. Pennisi M, Malaguarnera G, Puglisi V, Vinciguerra L, Vacante M, and Malaguarnera M. Neurotoxicity of acrylamide in exposed workers. Int J Environ Res Public Health. 10: 3843-3854. 2013. [Medline] [CrossRef]

9. Semla M, Goc Z, Martiniaková M, Omelka R, and Formicki G. Acrylamide: a common food toxin related to physiological functions and health. Physiol Res. 66: 205-217. 2017. [Medline] [CrossRef]

10. Mehri S, Karami HV, Hassani FV, and Hosseinzadeh H. Chrysin reduced acrylamide-induced neurotoxicity in both in vitro and in vivo assessments. Iran Biomed J. 18: 101106. 2014. [Medline]

11. Abdelall HF, ElGhamrawy TA, and Helmy D. Morphological evaluation of the protective role of dark soy sauce against acrylamide induced neurotoxicity in albino rats. Folia Morphol (Warsz). 74: 16-24. 2015. [Medline] [CrossRef]

12. Lai SM, Gu ZT, Zhao MM, Li XX, Ma YX, Luo L, and Liu J. Toxic effect of acrylamide on the development of hippocampal neurons of weaning rats. Neural Regen Res. 12: 1648-1654. 2017. [Medline] [CrossRef]

13. Yang HJ, Lee SH, Jin Y, Choi JH, Han CH, and Lee MH. Genotoxicity and toxicological effects of acrylamide on reproductive system in male rats. J Vet Sci. 6: 103-109. 2005. [Medline] [CrossRef]

14. Chapin RE, Fail PA, George JD, Grizzle TB, Heindel JJ, Harry GJ, Collins BJ, and Teague J. The reproductive and neural toxicities of acrylamide and three analogues in Swiss mice, evaluated using the continuous breeding protocol. Fundam Appl Toxicol. 27: 9-24. 1995. [Medline] [CrossRef]

15. Redin GS. Antibacterial activity in mice of minocycline, a new tetracycline. Antimicrob Agents Chemother. 6: $371-$ 376. 1966. [Medline]

16. Shultz RB, and Zhong Y. Minocycline targets multiple secondary injury mechanisms in traumatic spinal cord injury. Neural Regen Res. 12: 702-713. 2017. [Medline] [CrossRef]

17. Elewa HF, Hilali H, Hess DC, Machado LS, and Fagan SC. Minocycline for short-term neuroprotection. Pharmacotherapy. 26: 515-521. 2006. [Medline] [CrossRef]

18. Yrjänheikki J, Tikka T, Keinänen R, Goldsteins G, Chan $\mathrm{PH}$, and Koistinaho J. A tetracycline derivative, minocycline, reduces inflammation and protects against focal cerebral ischemia with a wide therapeutic window. Proc Natl Acad Sci USA. 96: 13496-13500. 1999. [Medline] [CrossRef]

19. Quintero EM, Willis L, Singleton R, Harris N, Huang P, Bhat N, and Granholm AC. Behavioral and morphological effects of minocycline in the 6-hydroxydopamine rat model of Parkinson's disease. Brain Res. 1093: 198-207. 2006. [Medline] [CrossRef]

20. Wang X, Zhu S, Drozda M, Zhang W, Stavrovskaya IG, Cattaneo E, Ferrante RJ, Kristal BS, and Friedlander RM. Minocycline inhibits caspase-independent and -dependent mitochondrial cell death pathways in models of Huntington's disease. Proc Natl Acad Sci USA. 100: 10483-10487. 2003. [Medline] [CrossRef]

21. Zhu S, Stavrovskaya IG, Drozda M, Kim BY, Ona V, Li M, Sarang S, Liu AS, Hartley DM, Wu DC, Gullans S, Ferrante RJ, Przedborski S, Kristal BS, and Friedlander RM. Minocycline inhibits cytochrome c release and delays progression of amyotrophic lateral sclerosis in mice. Nature. 417: 74-78. 2002. [Medline] [CrossRef]

22. Orazizadeh M, Hashemitabar M, and Khorsandi L. Protective effect of minocycline on dexamethasone induced testicular germ cell apoptosis in mice. Eur Rev Med Pharmacol Sci. 13: 1-5. 2009. [Medline]

23. LoPachin RM, Ross JF, Reid ML, Das S, Mansukhani S, and Lehning EJ. Neurological evaluation of toxic axonopathies in rats: acrylamide and 2,5-hexanedione. Neurotoxicology. 23: 95-110. 2002. [Medline] [CrossRef]

24. Bancroft JD, and Stevens A. Theory and Practice of Histological Technique. Churchill Livingstone, Edinburgh. 113-305. 1990.

25. Draper HH, and Hadley M. Malondialdehyde determination as index of lipid peroxidation. Methods Enzymol. 186: 421-431. 1990. [Medline] [CrossRef]

26. Pan X, Zhu L, Lu H, Wang D, Lu Q, and Yan H. Melatonin attenuates oxidative damage induced by acrylamide in vitro and in vivo. Oxid Med Cell Longev. 2015: 703709. 2015. [Medline] [CrossRef]

27. Garey J, and Paule MG. Effects of chronic low-dose acrylamide exposure on progressive ratio performance in adolescent rats. Neurotoxicology. 28: 998-1002. 2007. [Medline] [CrossRef]

28. Takahashi M, Shibutani M, Inoue K, Fujimoto H, Hirose M, and Nishikawa A. Pathological assessment of the nervous and male reproductive systems of rat offspring exposed maternally to acrylamide during the gestation and lactation periods - a preliminary study. J Toxicol Sci. 33: 11-24. 2008. [Medline] [CrossRef]

29. LoPachin RM, Barber DS, He D, and Das S. Acrylamide inhibits dopamine uptake in rat striatal synaptic vesicles. 
Toxicol Sci. 89: 224-234. 2006. [Medline] [CrossRef]

30. Huang WL, Ma YX, Fan YB, Lai SM, Liu HQ, Liu J, Luo L, Li GY, and Tian SM. Extract of Ginkgo biloba promotes neuronal regeneration in the hippocampus after exposure to acrylamide. Neural Regen Res. 12: 1287-1293. 2017. [Medline] [CrossRef]

31. Dortaj H, Yadegari M, Hosseini Sharif Abad M, Abbasi Sarcheshmeh A, and Anvari M. Stereological method for assessing the effect of vitamin $\mathrm{C}$ administration on the reduction of acrylamide-induced neurotoxicity. Basic Clin Neurosci. 9: 27-34. 2018. [Medline] [CrossRef]

32. El-Bakry AM, Abdul-Hamid M, and Allam A. Prenatal and perinatal exposure of acrylamide disrupt the development of spinal cord in rats. World J Neurosci. 3: 17-31. 2013. [CrossRef]

33. Al-Gholam MA, Nooh HZ, El-Mehi AE, El-Barbary A-M, and Fokar AZ. Protective effect of rosemary on acrylamide motor neurotoxicity in spinal cord of rat offspring: postnatal follow-up study. Anat Cell Biol. 49: 34-49. 2016. [Medline] [CrossRef]

34. Meistrich ML, and Hess RA. Assessment of spermatogenesis through staging. In: Spermatogenesis: Methods and Protocols, Methods in Molecular Biology of Seminiferous Tubules, T Douglas, DT Carrell, and KI Aston (eds.), Springer Science+Business Media. 299-307. 2013.

35. Mustafa HN. Effect of acrylamide on testis of albino rats. Ultrastructure and DNA cytometry study. Saudi Med J. 33: 722-731. 2012. [Medline]

36. Elghaffar SKA, Fiedan IO, Ahmed EA, Omar HEM. Acrylamide induced testicular toxicity in rats: protective effect of garlic Oil. Biomark J. 1:5. 2016.

37. Hasanin NA, Sayed NM, Ghoneim FM, and Al-Sherief SA. Histological and ultrastructure study of testes of acrylamide exposed adult male albino rat and evaluation of the possible protective effect of vitamin E intake. J Microsc Ultrastruct. 6: 23-34. 2018. [Medline] [CrossRef]

38. Kaçar S, Şahintürk V, Can B, and Musmul A. L-cysteine partially protects against acrylamide-induced testicular toxicity. Balkan Med J. 2018. (in press) [Medline]

39. Radad K, Moldzio R, and Rausch WD. Minocycline protects dopaminergic neurons against long-term rotenone toxicity. Can J Neurol Sci. 37: 81-85. 2010. [Medline] [CrossRef]

40. Cronin A, and Grealy M. Neuroprotective and neuro-restorative effects of minocycline and rasagiline in a zebrafish 6-hydroxydopamine model of Parkinson's disease. Neuroscience. 367: 34-46. 2017. [Medline] [CrossRef]

41. Park SI, Park SK, Jang KS, Han YM, Kim CH, and Oh SJ. Preischemic neuroprotective effect of minocycline and sodium ozagrel on transient cerebral ischemic rat model. Brain Res. 1599: 85-92. 2015. [Medline] [CrossRef]

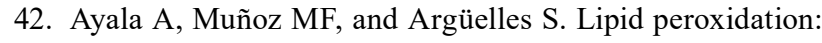
production, metabolism, and signaling mechanisms of malondialdehyde and 4-hydroxy-2-nonenal. Oxid Med Cell Longev. 2014: 360438. 2014. [Medline] [CrossRef]

43. Erdemli ME, Turkoz Y, Altinoz E, Elibol E, and Dogan Z. Investigation of the effects of acrylamide applied during pregnancy on fetal brain development in rats and protective role of the vitamin E. Hum Exp Toxicol. 35: 1337-1344. 2016. [Medline] [CrossRef]

44. Uthra C, Shrivastava S, Jaswal A, Sinha N, Reshi MS, and Shukla S. Therapeutic potential of quercetin against acrylamide induced toxicity in rats. Biomed Pharmacother. 86: 705-714. 2017. [Medline] [CrossRef]

45. Tabeshpour J, Mehri S, Abnous K, and Hosseinzadeh H. Neuroprotective effects of thymoquinone in acrylamideinduced peripheral nervous system toxicity through MAP kinase and apoptosis pathways in rat. Neurochem Res. 44: 1101-1112. 2019. [Medline] [CrossRef]

46. Lebda M, Gad S, and Gaafar H. Effects of lipoic Acid on acrylamide induced testicular damage. Mater Sociomed. 26: 208-212. 2014. [Medline] [CrossRef]

47. Goudarzi M, Mombeini MA, Fatemi I, Aminzadeh A, Kalantari H, Nesari A, Najafzadehvarzi H, and Mehrzadi S. Neuroprotective effects of Ellagic acid against acrylamideinduced neurotoxicity in rats. Neurol Res. 41: 419-428. 2019. [Medline] [CrossRef]

48. de Queiroz AIG, Chaves Filho AJM, Araújo TDS, Lima CNC, Machado MJS, Carvalho AF, Vasconcelos SMM, de Lucena DF, Quevedo J, and Macedo D. Antimanic activity of minocycline in a GBR12909-induced model of mania in mice: Possible role of antioxidant and neurotrophic mechanisms. J Affect Disord. 225: 40-51. 2018. [Medline] [CrossRef]

49. Czerny C, Kholmukhamedov A, Theruvath TP, Maldonado EN, Ramshesh VK, Lehnert M, Marzi I, Zhong Z, and Lemasters JJ. Minocycline decreases liver injury after hemorrhagic shock and resuscitation in mice. HPB Surg. 2012: 259512. 2012. [Medline] [CrossRef] 